\title{
Reliability of questionnaire information on cardiovascular disease and diabetes: cardiovascular disease study in Finnmark county
}

\author{
STEINAR TRETLI, ${ }^{1}$ PER G LUND-LARSEN, ${ }^{1}$ AND OLAV PER FOSS ${ }^{2}$ \\ From the National Mass Radiography Service, ${ }^{1}$ the Ullevaal Hospital, Central Laboratory, ${ }^{2}$ Oslo 1 , the Health \\ Service of Finnmark, Vads $\emptyset$, and the University of Troms $\emptyset$, Faculty of Medicine, Troms $\emptyset$, Norway
}

SUMMARY In a cardiovascular disease study in Finnmark county, Norway, which was repeated after three years (1977), 12694 men and women twice answered a questionnaire on myocardial infarction, angina pectoris, other heart diseases, atherosclerosis obliterans, stroke, and diabetes. The reliability of these data is studied by using different indicators. These indicators suggest that questionnaire information on myocardial infarction is reliable and more reliable than such information on stroke or on diabetes. For stroke the study showed an underreporting. The information from the question on other heart diseases and atherosclerosis obliterans seems so unreliable that an interpretation of such data may be difficult.

Several studies ${ }^{1-5}$ of cardiovascular disease and diabetes show methodological problems in the use of questionnaires and interviews. In a cardiovascular disease study in Finnmark county it was possible to show some indicators of the qualities of our questionnaire information because the same questionnaire was applied twice with an interval of three years. In addition, all those who gave a positive reply to questions on myocardial infarction, stroke, or diabetes at the first screening had their medical records checked at local health centres and county hospitals. Further, an infarction and stroke register was established for the three-year period between the two surveys to establish the true incidence. This study aims to present data on:

(1) The agreement between information obtained by questionnaires and by medical records for myocardial infarction, stroke, and diabetes.

(2) The reproducibility of positive questionnaire answers to inquiries about disease.

(3) The association between a positive history of disease in response to questions about angina pectoris or atherosclerosis obliterans, and answers about symptoms pointing towards such diseases.

(4) The association between questionnaire answers about diabetes and non-fasting serum glucose.

\section{Material and methods}

In 1974-5 everyone aged 35-49 years and a random $10 \%$ sample of those aged $20-34$ were invited to attend a screening examination for cardiovascular diseases and for some of the main risk factors (Finnmark I). Exactly three years after the first screening, an identical screening was carried out (Finnmark II).

The criteria for admission to Finnmark II were:

(1) Everyone aged 35-52 living in the county at the time of Finnmark II.

(2) All who had been invited to Finnmark I aged 23-28 still living in the county at the time of Finnmark II.

(3) A $10 \%$ random sample of those who had reached the age of 20 between the two surveys.

(4) An $11 \%$ random sample of people aged 20-34 not invited to Finnmark I.

The study population comprised 22612 people invited to Finnmark I or Finnmark II (116 at Finnmark I and 36 at Finnmark II attended the screening without invitation but were accepted for screening). Of those invited, $84.7 \%$ responded at Finnmark I and $84.8 \%$ at Finnmark II. At both screenings the response rate was slightly higher for women than for men. When the laboratory values are 
used in the analysis, the number of those included is slightly fewer than the number responding: 12694 responded at both Finnmark I and Finnmark II.

The questionnaire was printed on the reverse side of the invitation letter, and the recipients were asked to complete it at home and bring it to the screening station where each questionnaire was checked by a specially trained nurse. Omissions and inconsistencies were corrected in accordance with a written protocol. The questions, which are shown in the appendix, were formulated in accordance with the questions used in the Oslo study. ${ }^{6}$ In part $A$ the respondents were asked, "Have you, or have you had ..." a series of specified diseases. In part B they were asked whether they had a series of symptoms. Further details of the screenings are given elsewhere. ${ }^{7}$

Medical information was gathered from the local doctors, health centres, and county hospitals, and the doctors' recorded diagnoses were accepted without further investigations. We defined myocardial infarction, stroke, and diabetes as follows:

Myocardial infarction-Recorded diagnosis corresponding to ICD 8-410, 411, 412.

Stroke-Recorded diagnosis corresponding to ICD 8-430-436.

Diabetes mellitus-Recorded diagnosis corresponding to ICD 8-250, or information on diabetic drug treatment, or information on anti-diabetic dietetic treatment because of raised fasting serum glucose.

For everyone giving a positive reply at Finnmark I to questions on one or more of the mentioned diseases that could not be verified by the medical records, we investigated the person's medical background to find conditions that may have led to the supposed false reply. The myocardial infarction and stroke register was established independently of the answers to the questionnaire. The input consisted of notifications from doctors and information from hospitals, health centres, and sick bed records.

We accepted the following symptoms reported in the questionnaire as indicative of:

Angina pectoris-Pain in the chest during physical activity forcing the person to stop or slow down, which disappeared after less than 10 minutes' rest.

Atherosclerosis obliterans-Pain in the calf while walking, but not when at rest, increasing during physical activity and disappearing when activity stops.

\section{Results}

Table 1 shows the agreement between positive questionnaire answers at Finnmark I on myocardial infarction, stroke, and diabetes, and information obtained from medical records. The proportion of unverified positive answers is high for stroke and diabetes, but more acceptable for myocardial infarction. For those whose positive questionnaire answers on disease could not be verified, we investigated the existing medical information concerning the medical condition in the questionnaire. Many who gave a supposedly false-positive questionnaire answer had, according to this investigation, a logical reason for their answer, such as pericarditis presenting as chest pain which the patient reported as an infarct, or meningitis reported as a stroke, or a single episode of glycosuria reported as diabetes.

Table 2 shows the agreement between the independently registered episodes of myocardial infarction and stroke in the three-year interval between Finnmark I and II and the same persons' questionnaire answers on disease at Finnmark II. Out of 46 of those who had a registered myocardial infarction in the three-year period, $12(26 \%)$ denied their events, while as many as eight out of $12(67 \%)$ of the registered strokes were denied.

Table 3 shows the reproducibility at Finnmark II as a percentage of positive disease questionnaire answers at Finnmark I. The highest degree of reproducibility $(86 \%)$ was obtained for myocardial infarction. For positive questionnaire answers on angina pectoris and diabetes the reproducibility was about $73 \%$. For the other three diseases asked for in the questionnaire, the reproducibility was only $50 \%$ or less.

Table 4 shows the agreement between questionnaire answers on disease and answers on

Table 1 Agreement between positive questionnaire answers at Finnmark $I$ and information from medical records. (12 694 respondents at Finnmark I and II)

\begin{tabular}{lll}
\hline Do of positive & $\begin{array}{l}\text { questionnaire answers } \\
\text { at Finnmark I }\end{array}$ & $\begin{array}{l}\text { Positive questionnaire } \\
\text { answers verified by } \\
\text { medical records }\end{array}$ \\
\hline Myocardial & & $61(81 \%)$ \\
infarction & 75 & $20(65 \%)$ \\
Stroke & 31 & $29(66 \%)$ \\
Diabetes & 44 & \\
\hline
\end{tabular}

Table 2 Agreement between independently registered events between Finnmark $I$ and II and a positive answer to questions on history of disease at Finnmark II. (12 694 respondents at Finnmark I and II)

\begin{tabular}{llr}
\hline Disease & $\begin{array}{l}\text { No of registered events } \\
\text { between Finnmark I } \\
\text { and Finnmark II }\end{array}$ & $\begin{array}{l}\text { Positive questionnaire } \\
\text { answer at Finnmark II }\end{array}$ \\
\hline $\begin{array}{l}\text { Myocardial } \\
\text { infarction }\end{array}$ & 46 & 34 \\
$\begin{array}{l}\text { Stroke } \\
\text { and }\end{array}$ & 12 & $44 \%)$ \\
\hline
\end{tabular}


Table 3 Repeatability of positive answers to disease questions at Finnmark I. (12 694 respondents at both Finnmark I and Finnmark II)

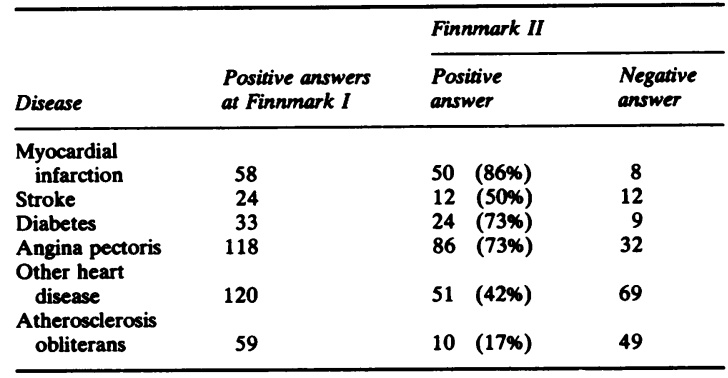

symptoms. About $65 \%$ of those who gave a questionnaire history of angina pectoris indicated symptoms pointing towards such disease. Of those who reported symptoms indicating angina pectoris in the questionnaire, $13 \%$ gave a questionnaire history of angina pectoris at Finnmark I and $25 \%$ at Finnmark II.

For those who gave a history of atherosclerosis obliterans, 15\% at Finnmark I and 35\% at Finnmark II indicated symptoms of atherosclerosis obliterans. Only $3 \%$ of those who indicated such symptoms gave a questionnaire history of atherosclerosis obliterans.
Table 5 shows percentage questionnaire symptom answers by different combinations of disease answers at the two screenings. The highest proportion of symptoms is seen for those reproducing at Finnmark II their positive answer on disease at Finnmark I. Those who did not repeat their first answer on disease tended to change answer on symptoms in the same direction as indicated for the disease.

Table 6 gives the relation between questionnaire answers on diabetes and non-fasting serum glucose. The serum glucose concentration indicates that those who twice stated that they had diabetes usually did have that disease. Many of those who gave a negative answer to the diabetes question at Finnmark I, but a positive answer at Finnmark II, possibly already had the disease at Finnmark I.

\section{Discussion}

Although medical records do not always represent the whole truth, it is useful to examine whether medical information obtained by a questionnaire can be verified by medical records. Of the myocardial infarctions reported in the questionnaires, $84 \%$ were verified. For infarctions reported but not verified, the usual finding was a history of "other heart disease."

Table 4 Agreement between questionnaire answers on disease and answers on symptoms. (12 694 respondents at Finnmark I and II)

\begin{tabular}{|c|c|c|c|c|c|}
\hline \multirow[b]{3}{*}{ Symptom } & \multirow{2}{*}{\multicolumn{2}{|c|}{$\frac{\text { Finnmark I }}{\text { History of condition }}$}} & \multirow[b]{3}{*}{ Symptom } & \multirow{2}{*}{\multicolumn{2}{|c|}{$\begin{array}{l}\text { Finnmark II } \\
\text { History of condition }\end{array}$}} \\
\hline & & & & & \\
\hline & Positive & Negative & & Positive & Negative \\
\hline \multicolumn{6}{|c|}{ Angina pectoris } \\
\hline $\begin{array}{l}\text { Positive } \\
\text { Negative }\end{array}$ & $\begin{array}{l}79 \\
39\end{array}$ & $\begin{array}{r}524 \\
12052\end{array}$ & $\begin{array}{l}\text { Positive } \\
\text { Negative }\end{array}$ & $\begin{array}{r}133 \\
79\end{array}$ & $\begin{array}{r}403 \\
12079\end{array}$ \\
\hline All & 118 & 12576 & All & 212 & 12482 \\
\hline \multicolumn{6}{|c|}{ Atherosclerosis } \\
\hline $\begin{array}{l}\text { Positive } \\
\text { Negative }\end{array}$ & $\begin{array}{r}9 \\
50\end{array}$ & $\begin{array}{r}332 \\
12633\end{array}$ & $\begin{array}{l}\text { Positive } \\
\text { Negative }\end{array}$ & $\begin{array}{l}15 \\
27\end{array}$ & $\begin{array}{r}531 \\
12121\end{array}$ \\
\hline All & 59 & 12665 & All & 42 & 12652 \\
\hline
\end{tabular}

Table 5 Questionnaire symptom answers by questionnaire disease answers at Finnmark I/Finnmark II. (12 694 respondents at Finnmark $I$ and II)

\begin{tabular}{|c|c|c|c|c|}
\hline \multirow[b]{2}{*}{ Disease } & \multirow{2}{*}{$\begin{array}{l}\text { Questionnaire answer at } \\
\text { Finnmark I/Finnmark II }\end{array}$} & \multirow[b]{2}{*}{ No } & \multicolumn{2}{|c|}{$\begin{array}{l}\text { Percentage with questionnaire } \\
\text { symptom answers indicating } \\
\text { specified disease at }\end{array}$} \\
\hline & & & Finnmark I & Finnmark II \\
\hline Atherosclerosis obliterans & $\begin{array}{l}\text { Positive/positive } \\
\text { Positive/negative } \\
\text { Negative/positive } \\
\text { Negative/negative } \\
\text { Positive/positive } \\
\text { Positive/negative } \\
\text { Negative/positive } \\
\text { Negative/negative }\end{array}$ & $\begin{array}{r}86 \\
32 \\
126 \\
12448 \\
10 \\
49 \\
32 \\
12602\end{array}$ & \begin{tabular}{r|}
$73 \cdot 3$ \\
$50 \cdot 0$ \\
$31 \cdot 0$ \\
3.9 \\
$30 \cdot 0$ \\
12.2 \\
12.5 \\
2.6
\end{tabular} & $\begin{array}{r}67 \cdot 4 \\
15 \cdot 6 \\
59 \cdot 5 \\
3 \cdot 2 \\
40 \cdot 0 \\
4 \cdot 1 \\
34 \cdot 4 \\
4 \cdot 2\end{array}$ \\
\hline
\end{tabular}


All the positive disease answers that could not be verified seemed to be false, but there were often logical reasons for many of the false answers.

The number of cases of diabetes that were not reported (the false-negatives) could not be counted in this study. For myocardial infarction and stroke, however, the questionnaire answers at Finnmark II by those who had had a registered event of those diseases in the period gave an indication of the degree of underreporting. While most of the registered myocardial infarctions were reported, only a third of the strokes were reported.

Some new events occurred in the three-year period between the two screenings. Therefore, when applying reproducibility of questionnaire answers as a measure of reliability, we had to measure the reproducibility only in the group who gave a positive answer on disease at Finnmark I (table 3). For some, these data may be influenced by contact with the local doctors in connection with the follow-up examinations after the first screening. Nevertheless, the reproducibility of positive answers on disease as a measure of reliability is no less suitable because of this influence. Table 3 suggests that the well-defined diseases reproduce better than the badly defined.

In tables 4 and 5 we have tried to indicate the reliability of questionnaire answers by showing agreement between questionnaire history of angina pectoris and atherosclerosis obliterans and symptoms pointing towards such diseases. We are aware that not all cases of diagnosed angina pectoris and atherosclerosis obliterans will necessarily have a symptom constellation meeting our criteria for acceptable symptoms as indicative of such disease. Table 4 shows a much higher degree of accordance between symptoms and disease questions for angina pectoris than for atherosclerosis obliterans. The highest degree of accordance (table 5) is obtained for both conditions when there is a positive disease answer at both screenings. It is impossible to establish, however, if it is the question on symptoms or disease, or both, that are not specific enough. It is also interesting to note the large number reporting symptoms without a history and specially the large number giving a history of atherosclerosis without symptoms. In our opinion the questions on atherosclerosis obliterans are of little value as epidemiological indicators.

In table 6 we have used non-fasting serum glucose as an indicator of reliability of reported diabetes. The glucose concentration for respondents reporting diabetes twice is very close to the concentration found for those who had a verified diabetes answer. The table suggests that respondents first reporting diabetes, and then denying it, gave a false-positive answer on diabetes at Finnmark $\mathbf{I}$.
Table 6 Finnmark I and II (aged 35-49 at Finnmark I). Relationship between questionnaire answers to a history of diabetes and non-fasting serum glucose, (age-adjusted)

\begin{tabular}{|c|c|c|c|c|}
\hline \multirow{3}{*}{$\begin{array}{l}\text { Questionnaire answers } \\
\text { on a history of } \\
\text { diabetes at } \\
\text { Finnmark I/Finnmark II }\end{array}$} & \multicolumn{4}{|c|}{$\begin{array}{l}\text { Non-fasting serum glucose concentration } \\
\text { (mmol/l) }\end{array}$} \\
\hline & \multicolumn{2}{|c|}{ Finnmark I } & \multicolumn{2}{|c|}{ Finnmark II } \\
\hline & No & Mean & No & Mean \\
\hline $\begin{array}{l}\text { Positive/positive } \\
\text { Positive/negative } \\
\text { Negative/positive } \\
\text { Negative/negative }\end{array}$ & $\begin{array}{r}22 \\
8 \\
31 \\
9434\end{array}$ & $\begin{array}{l}9 \cdot 54 \\
5 \cdot 79 \\
7 \cdot 51 \\
5 \cdot 72\end{array}$ & $\begin{array}{r}22 \\
8 \\
32 \\
9427\end{array}$ & $\begin{array}{r}10 \cdot 07 \\
6 \cdot 16 \\
8 \cdot 06 \\
5 \cdot 91\end{array}$ \\
\hline
\end{tabular}

When questionnaire data is used to obtain prevalence data for myocardial infarction, the degree of underreporting seems to equal the degree of overreporting. This means that the prevalence figure for myocardial infarction obtained by questionnaire is more or less the same as the prevalence figure based on medical records. For stroke, however, there seems to be considerable underreporting. For the other diseases covered by the questionnaire it is difficult to quantify over and underreporting. Questionnaire information may be difficult to interpret, but despite this it is of obvious interest to state changes in such information from one point of time to another. We think it is necessary to mark such information-for instance, by using words like "questionnaire prevalence." It seems also necessary to exercise caution, especially when making comparisons. The language and phrasing of the questionnaire, the examination procedure, the level of education of the population, the health service system, and response rate should all be taken into account. Under identical examination or re-examination conditions the questionnaire information may be of value-for example, when studying differences in questionnaire prevalence between areas or in the same area over time.

\section{Appendix}

PART A

Have you, or have you had: myocardial infarction, angina pectoris (heart cramp), other heart diseases, arteriosclerosis of legs, cerebral stroke, diabetes?

\section{PART B}

Do you get pain or discomfort in the chest when: walking up hills, stairs, or hurrying on level ground; walking at ordinary pace on the level?

If you get pain or discomfort in the chest when walking, do you usually: stop, slow down, carry on at same pace?

If you stop or slow down, does the pain disappear: after less than 10 minutes, after more than 10 minutes? 
Do you get pain in the calf while you are: walking, resting?

If you get pain in the calves does the pain increase at faster pace or uphill, and does the pain disappear when you stop?

\section{References}

${ }^{1}$ National Centre for Health Statistics; Interview data on chronic conditions compared with information derived from medical records. NCHS, 1967. (Public Health Service Publication No 1000-Series 2-No 23.)

${ }^{2}$ Rose GA. Variability of angina. Br J Prev Soc Med 1968; 22: 12-5.
${ }^{3}$ Zeiner-Henriksen T. Comparison of personal interview and postal inquiry methods for assessing prevalence of angina pectoris and possible infarction. $J$ Chronic Dis 1972; 25: 433-40.

${ }^{4}$ Gillum RF, Feinleib M, Margolis JR, Fabsitz RR, Brasch RC. Some methodological problems in the community study of cardiovascular disease. J Chronic Dis 1976; 29: 289-99.

${ }^{5}$ Gordis L. Assuming the quality of questionnaire data in epidemiological research. Am J Epidemiol 1979; 109: 21-4.

${ }^{6}$ Leren P, Askevold EM, Foss OP, et al. The Oslo study. Cardiovascular disease in middle-aged and young Oslo men. Acta Med Scand 1975; 588 (suppl).

${ }^{7}$ Bjartveit K, Foss OP, Gjervig T, Lund-Larsen PG. The cardiovascular disease study in Norwegian counties. Background and organization. Acta Med Scand 1979; 634 (suppl). 